\title{
Mathematical Predictions of Neuropathic Diabetes from Unit Level Data
}

\author{
P. Sankar ${ }^{1}$, T. Subhramaniyan ${ }^{2}$, J. Jayanthi ${ }^{3}$, M.G. Ragunathan ${ }^{4}$ \\ ${ }^{1,2}$ Department of Mathematics, Guru Nanak College, Chennai, India \\ ${ }^{3,4}$ Associate Professor, Department of Advanced Zoology and Biotechnology \\ Guru Nanak College, Chennai, India
}

*Corresponding Author: P. Sankar, Department of Mathematics, Guru Nanak College, Chennai, India.

\begin{abstract}
The purpose of this study is to examine the factors which determines the neuropathic diabetes. The study considered family background, smoking, alcoholic habits and pattern of exercise influence of neuropathic diabetes. The study adopted association test, mean difference test to make inference about the pattern of relationship existing between the factors under analysis. The study clearly depicts that gender is unbiased factor in terms of having diabetes. There is a strong association between diabetic nature and family background, habits and pattern of exercises. The study concludes that age, food habits and regular exercise are important factors which inhibits the diabetes.
\end{abstract}

Keywords: Neuropathic diabetes - Chi-square test-Determinants- Food habits.

\section{INTRODUCTION}

Diabetes is a chronic [1] and one of the dramatically increasing metabolic disorder in the World. It is a global health problem. Recent statistics shows that the number of people living with diabetes is expected to rise from 366 million in 2011 to 552 million by 2030 if no urgent action is taken [2,3]. The prevalence of diabetes in India is increasing at a fast rate. Diabetes is associated with an abnormal increase in the level of glucose in blood, ensued either owing to the inadequate production of insulin by pancreas or the cell failure in the effective response to insulin produced by pancreas. The former is called Type 1 diabetes and the later is Type 2 diabetes[4]. The downside of all this variability in plasma glucose is that it leads to severe damage to many of the body's vital systems especially blood vessels and the nervous system. While it causes are not yet entirely understood, Medical Scientists believe that both genetic factors and environmental triggers are involved therein. However, diabetes used to be most prevalent in adults and once called adult-onset diabetes. It is now widely believed that diabetes mellitus is closely related with the aging process. Diabetes results from the interaction between a genetic predisposition, behavioral and environmental risk factors [5]. Although the genetic basis of type 2 diabetes has yet to be identified, there is strong evidence that such modifiable risk factors as obesity and physical inactivity are the main non-genetic determinants of the disorder [6]. Lifestyle factors linked to the incidence of diabetes or diabetes-related risk factors include physical activity level, dietary habits, adiposity, alcohol consumption, smoking [7-16] and duration of sleep $[17,18]$. The World Health Organization (WHO) recommends the development of simple strategies to identify those at risk of diabetes and provide them with early lifestyle interventions [19]. It is very important to establish predictive models using those risk factors for interventions relating to the development of diabetes. Previous studies have suggested that anthropometry measurement and adipocyte size can serve as predictors of diabetes incidence using traditional statistical methods [2023].

To gain a better understanding about neuropathic diabetes and non-neuropathic diabetes to treatment it was analysed for the association between clinical factors such as smoking, alcohol habits, blood pressure, body mass index and previous blood pressure or BMI, need of insulin treatment after diagnosis. 


\section{MATERIALS AND MethodS}

The dataset used in the study has been collected from the Dr. Mohan diabetes specialities centre database. The database containing 1393 records and each record containing several information including demographic particulars of the patients, family history, personal habits and food consumption behaviour were collected. A family history is defined as any member previously have been diagnosed as having diabetes by a physician. Height and weight of the patients were also recorded. BMI was calculated. SPSS version 24 (IBM Corporation) was used for all Statistical analyses. A two sided p-value of 0.05 was considered statistically significant.

\subsection{Chi-square test}

By definition of the Chi-square random variable with $n$ degrees of freedom is given by

$$
\chi^{2}=X_{1}^{2}+X_{2}^{2}+\cdots+X_{n}^{2} .
$$

Where $X_{j}{ }^{\prime} s$ are all independent and have $N(0,1)$ distributions. Also recall that $\chi^{2}$ has a gamma distribution with parameters $\theta=\frac{n}{2}$ and $\phi=\frac{1}{2}$.

$$
\text { Let } f(x)=\left(\frac{1}{2}\right)^{\frac{n}{2}} \frac{x^{\frac{n}{2}-1} e^{-\theta x}}{\Gamma\left(\frac{n}{2}\right)}
$$

Where $\Gamma(t)$ is a gamma function, given by

$$
\Gamma(t)=\int_{0}^{\infty} x^{t-1} e^{-x} d x, \text { for } t>0
$$

Then, we are saying that

$$
P\left(\chi^{2} \geq \alpha\right)=\int_{0}^{\infty}\left(\frac{1}{2}\right)^{\frac{n}{2}} \frac{x^{\frac{n}{2}-1} e^{-\theta x}}{\Gamma\left(\frac{n}{2}\right)} d x
$$

\section{Chi-square follows gamma distribution}

Theorem 1: For large values of $M$, the random variable $E=\sum_{i=1}^{n} \frac{\left(X_{i}-p_{i} M\right)^{2}}{p_{i} M}$ has approximately a Chi-square distribution with $n-1$ degrees of freedom.

Theorem 2:Suppose that $X$ and $Y$ are continuous random variables having moment generating functions $M_{X}(t)=E\left(e^{t X}\right)$ and $M_{Y}(t)=E\left(e^{t Y}\right)$, respectively. Further, suppose that these functions exist for all $t$ in a neighbourhoodof 0 and that they are continuous at $t=0$. Then

$$
P(X \leq \alpha)=P(Y \leq \alpha) \text { for all } \alpha \Leftrightarrow M_{X}(t)=M_{Y}(t) .
$$

Theorem 3:If $\chi^{2}$ is a random variable having $n$ degrees of freedom, and if $Z$ is a random variable that obeys a gamma distribution with parameters $\theta=\frac{n}{2}$ and $\phi=\frac{1}{2}$, then we have that

$$
P\left(\chi^{2} \geq \alpha\right)=P(Z \geq \alpha) .
$$

Now recall that (i) If $n$ is a positive even integer we get that $\Gamma\left(\frac{n}{2}\right)=\left(\frac{n}{2}-1\right) !$, which gives that 


$$
P\left(\chi^{2} \geq \alpha\right)=P(Z \geq \alpha)=\frac{1}{\left(\frac{n}{2}-1\right) !}\left(\frac{1}{2}\right)^{\frac{n}{2}} \int_{\alpha}^{\infty} x^{\frac{n}{2}-1} e^{-\frac{x}{2}} d x
$$

Then the right-most expression equals the sum of probabilities of a certain Poisson random variable. If $Y$ is Poisson random variable with parameter $\frac{\alpha}{2}$, then we have that

$$
\begin{gathered}
P\left(\chi^{2} \geq \alpha\right)=P(Z \geq \alpha)=\sum_{i=1}^{\frac{n}{2}-1} P(Y=i) \\
=e^{-\frac{\alpha}{2}} \sum_{i=0}^{\frac{n}{2}-1} \frac{(\alpha / 2)^{i}}{i !}
\end{gathered}
$$

(ii) If $n$ is a positive odd integer we get that $\Gamma\left(\frac{n+1}{2}\right)=\left(\frac{n+1}{2}-1\right) !$, which gives that

$$
P\left(\chi^{2} \geq \alpha\right)=P(Z \geq \alpha)=\frac{1}{\left(\frac{n+1}{2}-1\right) !}\left(\frac{1}{2}\right)^{\frac{n+1}{2}} \int_{\alpha}^{\infty} x^{\frac{n+1}{2}-1} e^{-\frac{x}{2}} d x
$$

then the Poisson distribution with parameter $\frac{\alpha}{2}$ is

$$
\begin{aligned}
P\left(\chi^{2} \geq \alpha\right)=P(Z \geq \alpha)=\sum_{i=1}^{\frac{n+1}{2}-1} P(Y & =i) \\
& =e^{-\frac{\alpha}{2} \sum_{i=0}^{\frac{n+1}{2}-1} \frac{(\alpha / 2)^{i}}{i !}}
\end{aligned}
$$

\subsection{Mean Comparison Test: Two Sample $t$ test}

We now have three dimensional parameter space $\theta=\left\{\left(\mu_{1}, \mu_{2}, \sigma^{2}\right) ; \mu_{1}, \mu_{2}, \sigma^{2} \in R\right\}$.

The two-sided test is

$$
H_{0}: \mu_{1}=\mu_{2} \text { and } \mu_{1} \neq \mu_{2} \text {. }
$$

The data $X_{1, j}, \cdots \cdots \cdots X_{n_{j}, j}$ are independent $N\left(\mu_{j}, \sigma^{2}\right)$ random variables, $j=1,2$.

The likelihood function is

$$
L\left(\mu_{1}, \mu_{2}, \sigma^{2} / X_{1}, X_{2}\right)=\frac{1}{\left(2 \pi \sigma^{2}\right)^{\left(n_{1}+n_{2}\right) / 2}} \exp -\frac{1}{2 \sigma^{2}}\left(\sum_{i=1}^{n_{1}}\left(x_{i, 1}-\mu_{1}\right)^{2}+\sum_{i=1}^{n_{2}}\left(x_{i, 2}-\mu_{2}\right)^{2}\right) \text {. }
$$

Then, the likelihood ratio,

$$
\Lambda\left(X_{1}, X_{2}\right)=\frac{L\left(\hat{\mu}, \hat{\mu}, \hat{\sigma}^{2} / X_{1}, X_{2}\right)}{L\left(\hat{\mu}_{1}, \hat{\mu}_{2}, \hat{\sigma}_{12}^{2} / X_{1}, X_{2}\right)}
$$

Write the unbiased estimators for the mean and variance 


$$
\bar{x}_{j}=\frac{1}{n_{j}} \sum_{i=1}^{n_{j}} x_{i, j} \text { and } s_{j}^{2}=\frac{1}{n_{j}-1} \sum_{i=1}^{n_{j}}\left(x_{i, j}-\bar{x}_{j}\right)^{2}, j=1,2
$$

Then, the overall maximum likelihood estimators are

$$
\hat{\mu}_{1}=\hat{x}_{1}, \hat{\mu}_{2}=\hat{x}_{2}, \quad \hat{\sigma}^{2}=\frac{\left(n_{1}-1\right) s_{1}^{2}+\left(n_{2}-1\right) s_{2}^{2}}{n_{1}+n_{2}} .
$$

The maximum likelihood estimators in the numerator takes place on the set $\mu_{1}=\mu_{2}$.

$$
\hat{\mu}=\frac{n_{1} \bar{x}_{1}+n_{2} \bar{x}_{2}}{n_{1}+n_{2}}, \quad \hat{\sigma}_{12}^{2}=\frac{1}{n_{1}+n_{2}}\left(\sum_{i=1}^{n_{1}}\left(x_{i, 1}-\hat{\mu}\right)^{2}+\sum_{i=1}^{n_{2}}\left(x_{i, 2}-\hat{\mu}\right)^{2}\right)
$$

Thus yields the test statistic

$$
T\left(X_{1}, X_{2}\right)=\frac{\bar{x}_{1}-\bar{x}_{2}}{\sqrt{\left(\frac{1}{n_{1}}+\frac{1}{n_{2}}\right)\left(\frac{\left(n_{1}-1\right) s_{1}^{2}+\left(n_{2}-1\right) s_{2}^{2}}{n_{1}+n_{2}-2}\right)}}
$$

From the fact that the likelihood ratio

$$
\Lambda\left(X_{1}, X_{2}\right)=\left(\frac{n_{1}+n_{2}-2}{n_{1}+n_{2}-2+T\left(X_{1}, X_{2}\right)^{2}}\right)^{2 /\left(n_{1}+n_{2}\right)}
$$

Under the null hypothesis, $T\left(X_{1}, X_{2}\right)$ has a $t$-distribution with $n_{1}+n_{2}-2$ degrees of freedom.

\subsection{Results and Discussion}

As mentioned earlier, the dataset used in the study was obtained from the Dr. Mohan diabetes specialities centre database. Table 1 produces summary statistics of the variables used in the study. From the baseline survey, it was found that the mean age of the neuropathic diabetes was 64.93 years, $33 \%$ were smokers, $24.55 \%$ were alcoholic during the first visit of the treatment. Also, it is inferred that mean time staying at hospital for treatment was 14.01 months, height $163 \mathrm{~cm}$, weight $69.9 \mathrm{~kg}$. Body mass index (BMI) was calculated as weight in kilograms divided by the square of height in meters $\left(\mathrm{kg} / \mathrm{m}^{2}\right)$, Waist 26.3 inches, Hip $98.61 \mathrm{cms}$, Diastolic Blood Pressure 81.01 and Systolic Blood pressure 134.33. The following results shows that before(first visit) and after treatment (last visit). HbA1c in first visit was 9.08 and in last visit was 8.23, Cholesterol in first visit was 175.99 and in last visit 149.70, HDL cholesterol in first visit was 40.36 and in last visit 38.30, LDL cholesterol in first visit was 102.5 and in last visit 82.10 , Urea in first visit was 26.64 and in the last visit 27.85, Creatinine in first visit was 0.88 and in the last visit 0.93 . It is medically proved that if Great toe right or left is greater than are equal to 20 then the patient is called diabetic under neuropathy.

\section{TABLES}

Table 1. Statistics Summary

\begin{tabular}{|l|c|c|c|}
\hline Variables & $\mathrm{N}$ & Mean & S.D \\
\hline Age & 376 & 64.93 & 8.096 \\
\hline Dur_dm_no & 376 & 14.01 & 8.045 \\
\hline Height & 376 & 163 & 9.11 \\
\hline Weight & 376 & 69.9 & 13.12 \\
\hline Bmi & 376 & 26.3 & 4.42 \\
\hline Waist & 376 & 26.3 & 10.63 \\
\hline Hip & 376 & 98.61 & 9.57 \\
\hline Dia bp & 376 & 81.01 & 9.38 \\
\hline Sys_bp & 376 & 134.33 & 20.41 \\
\hline FV_hba & 376 & 9.08 & 2.07 \\
\hline LV_hba & 376 & 8.23 & 1.78 \\
\hline FV_cho & 376 & 175.99 & 49.51 \\
\hline
\end{tabular}


Mathematical Predictions of Neuropathic Diabetes from Unit Level Data

\begin{tabular}{|l|c|c|c|}
\hline \hline LV_cho & 376 & 149.70 & 39.21 \\
\hline FV_tri & 376 & 174.18 & 228.51 \\
\hline LV_tri & 376 & 148.85 & 89.68 \\
\hline FV_hdl & 376 & 40.36 & 10.64 \\
\hline LV_hdl & 376 & 38.30 & 10.78 \\
\hline FV_ldl & 376 & 102.5 & 36.02 \\
\hline LV_ldl & 376 & 82.10 & 31.15 \\
\hline FV_ure & 376 & 26.64 & 12.22 \\
\hline LV_ure & 376 & 27.85 & 11.41 \\
\hline FV_cre & 376 & 0.88 & 0.29 \\
\hline LV_cre & 376 & 0.93 & 0.38 \\
\hline Gre_toe_RT & 376 & 26.39 & 7.52 \\
\hline Gre_toe_LT & 376 & 26.13 & 7.55 \\
\hline
\end{tabular}

F.V-First Visit, L.V-Last Visit.

Table 2. Association between Demographic factors and diabetes

\begin{tabular}{|c|c|c|c|c|c|}
\hline Characteristics & $\begin{array}{l}\text { Neuropathy } \\
\mathrm{N}=376\end{array}$ & $\begin{array}{l}\text { Non-Neuropathy } \\
\mathrm{N}=1017\end{array}$ & $\begin{array}{l}\text { Total } \\
\mathrm{N}=1393\end{array}$ & Pearson Chi-Square & p-value \\
\hline \multicolumn{6}{|c|}{ Gender } \\
\hline Male & 255 & 645 & 900 & \multirow[t]{2}{*}{2.321} & \multirow[t]{2}{*}{0.128} \\
\hline Female & 121 & 372 & 493 & & \\
\hline \multicolumn{6}{|c|}{ Age } \\
\hline $30-39$ & 0 & 45 & 45 & \multirow{6}{*}{225.313} & \multirow{6}{*}{0.000} \\
\hline $40-49$ & 13 & 206 & 219 & & \\
\hline $50-59$ & 74 & 395 & 469 & & \\
\hline $60-69$ & 178 & 297 & 475 & & \\
\hline $70-79$ & 93 & 65 & 158 & & \\
\hline $80-89$ & 18 & 9 & 27 & & \\
\hline \multicolumn{6}{|c|}{ Diabetic Father } \\
\hline Yes & 122 & 443 & 565 & \multirow[t]{2}{*}{14.061} & \multirow[t]{2}{*}{0.000} \\
\hline No & 254 & 574 & 828 & & \\
\hline \multicolumn{6}{|c|}{ Diabetic Mother } \\
\hline Yes & 112 & 411 & 523 & \multirow[t]{2}{*}{13.218} & \multirow[t]{2}{*}{0.000} \\
\hline No & 264 & 606 & 870 & & \\
\hline \multicolumn{6}{|l|}{ Sibling } \\
\hline Yes & 202 & 476 & 678 & \multirow[t]{2}{*}{5.260} & \multirow[t]{2}{*}{0.022} \\
\hline No & 174 & 541 & 715 & & \\
\hline \multicolumn{6}{|c|}{ Smoking Habit } \\
\hline Yes & 100 & 203 & 303 & \multirow[t]{2}{*}{7.100} & \multirow[t]{2}{*}{0.008} \\
\hline No & 276 & 814 & 1090 & & \\
\hline \multicolumn{6}{|c|}{ Alcohol Consuming Habit } \\
\hline Yes & 82 & 252 & 334 & \multirow[t]{2}{*}{8.329} & \multirow[t]{2}{*}{0.024} \\
\hline No & 294 & 765 & 1059 & & \\
\hline \multicolumn{6}{|c|}{ Exercise } \\
\hline Exercise & 130 & 331 & 461 & \multirow[t]{2}{*}{13.69} & \multirow[t]{2}{*}{0.251} \\
\hline No Exercise & 246 & 686 & 935 & & \\
\hline
\end{tabular}

Source: Computed.

The basic objective of the study is to examine the factors determining the nature of neuropathy. The study has applied Chi-square test as the test is best measurement of association between categorical data. Accordingly, Chi-square test has been applied and the results are presented in the table 2 .

\section{Hypothesis 1: There is no association between age and prevalence of diabetes.}

The computational process of deriving Chi-square and probability value is discussed here. The sample data furnished in table 2 are used for the computation. The Chi-square value for the above table is

$$
E=\sum_{i=1}^{n} \frac{\left(X_{i}-p_{i} M\right)^{2}}{p_{i} M}
$$

$E=12.25+35.97+21.85+19.34+59.44+15.74+4.49+13.29+2.97+7.15+21.98+5.82$ 
$=220.19$

The probability value with $n=5$ degrees of freedom is

$$
\begin{gathered}
P\left(\chi^{2} \geq 220.19\right)=e^{-220.19 / 2} \sum_{i=0}^{2} \frac{(220.19 / 2)^{i}}{i !} \\
=9.432160885 \times 10^{-45} \\
\approx 0.000
\end{gathered}
$$

From the computation, it is learnt that the computed Chi-square value is greater than the table value (3.84) as well as the computed $p$ - value is less than 0.05 , therefore the study rejects the null hypothesis that there is no association between age and prevalence of diabetes. The study based on the statistical results arrives to conclude that the nature of diabetes is dependent on age. It is practically true that as growing age shall invite many health complications. Diabetes is fast growing disorder among the old age people. It is not only the result of age factor it is due to many of the other factors such as food habits, lack of exercise, etc.

\section{Diabetes is Genetical}

Genetics play a strong role in the chances of developing both type 1 and type 2 diabetes. Other factors include environment and lifestyle. The risk of developing diabetes is affected by whether your parents or siblings have diabetes. Blood relatives of people with either type 1 or type 2 diabetes also have a higher risk of developing the same type of diabetes as their family member.

\section{Hypothesis 2: There is no association between Family Diabetics History and nature of Diabetes}

Based on the above theoretical consideration, the study tries to examine whether there is any association between family diabetic history and nature of diabetes. Here the family history implies that if a patient's father or mother or siblings have diabetes or not. The Chi-square values for the parameter are provided in the Table 2. As it is evident from the table the computed $p$-value is less than 0.05 , the study rejects the null hypothesis and arrives to conclude that family diabetic history plays a significant role in diabetes. As it is evident from many studies that diabetes is a genetic one.

\section{Nature of Habits}

Habits determine the well-being of a person. If a person follow good virtue and habit, he/she would enjoy the life and vice- versa. Especially for some epidemic disorder, habits play a crucial role in its determination. In the case of diabetes, smoking and alcoholic habits are prominent factors. Accordingly, the study intends to examine whether there is any association between habits and nature of diabetes.

\section{Hypothesis 3: There is no associationbetweenSmoking, Alcohol consumption and prevalence of diabetes}

The Chi-square value and $p$-value are greater than the table value and less than 0.05 respectively. To reject the null hypothesis that there is no association between smoking, alcohol habit andprevalence of diabetes.In conclusion, a low proportion of type 2 diabetic patients were smokers and alcohol intakedue to lack of proper awareness and education on the effect of smoking andalcohol intake on diabetes, the disorder is spreading widely and silently into other countries in world. In more than half of the patients found that smoking did not give improvement rather than worsens their type 2 diabetes. People with diabetes already have an increased risk of developing diabetic related complications and this will further elevate if they smoke.

\section{Nature of Exercise}

Physical activity or Exercise has been shown to be instrumental in preventing diabetes among people at high risk and in helping to manage symptoms in people with the disorder. Abnormal insulin secretion and peripheral insulin resistance are primary factors that influence the acute effects of physical activity on metabolic responses in those with type 2 diabetes. Several factors including muscle fiber composition, low capillary density, obesity and older age require that physical activity be 
initiated at lower intensity/duration and be increased gradually to reduce risks and contribute to maintenance of physical activity by those with type 2 diabetes.

\section{Hypothesis 4: There is no association between Exercise and prevalence of diabetes}

The Chi-square value and $\mathrm{p}$ - value are greater than the table value and less than 0.05 respectively. To reject the null hypothesis that there is no association between exercise and prevalence of diabetes. In conclusion, Physical activity affords significant acute and chronic benefits for those with type 2 diabetes. The benefits of chronic physical activity are more numerous than those of acute physical activity, emphasizing the need for regular participation by those with type 2 diabetes and those at risk for this form of diabetes. It concludes that diet and regular exercise were more effective than one of the most widely prescribed drug treatments for preventing diabetes.

\section{Food Consumption induces Diabetics:}

Table 3. Changes in Food Consumption

\begin{tabular}{|c|c|c|c|c|c|}
\hline Variables & $\mathbf{N}$ & Mean & S.D & Std. Error & 't' value \\
\hline Calorie_FV & 376 & 1259.35 & 359.24 & 18.85 & \multirow[t]{2}{*}{-0.86} \\
\hline Calorie_LV & 376 & 1280.08 & 355.78 & 18.68 & \\
\hline Protein_FV & 376 & 45.82 & 11.69 & 0.613 & \multirow[t]{2}{*}{-0.50} \\
\hline Protein_LV & 376 & 46.21 & 11.98 & 0.629 & \\
\hline Carbo_FV & 376 & 204.40 & 63.38 & 3.32 & \multirow[t]{2}{*}{-1.14} \\
\hline Carbo_LV & 376 & 209.35 & 61.45 & 3.22 & \\
\hline Fat_FV & 376 & 30.43 & 17.40 & 0.91 & \multirow[t]{2}{*}{-0.242} \\
\hline Fat_LV & 376 & 30.68 & 14.21 & 0.74 & \\
\hline Satfat_FV & 376 & 1.65 & 4.90 & 0.25 & \multirow[t]{2}{*}{$3.941 * *$} \\
\hline Satfat_LV & 376 & 0.61 & 1.54 & 0.08 & \\
\hline Pufa_FV & 376 & 1.29 & 3.03 & 0.16 & \multirow[t]{2}{*}{$6.298 * *$} \\
\hline Pufa_LV & 376 & 0.31 & 1.04 & 0.05 & \\
\hline Fibre_FV & 376 & 4.75 & 14.51 & 0.76 & \multirow[t]{2}{*}{$-10.40 * *$} \\
\hline Fibre_LV & 376 & 15.43 & 13.26 & 0.69 & \\
\hline Sodium_FV & 376 & 143.17 & 460.74 & 24.18 & \multirow[t]{2}{*}{$3.526 * *$} \\
\hline Sodium_LV & 376 & 58.40 & 206.02 & 10.81 & \\
\hline Potas_FV & 376 & 94.08 & 143.49 & 7.53 & \multirow[t]{2}{*}{$6.940 * *$} \\
\hline Potas_LV & 376 & 34.35 & 97.21 & 5.10 & \\
\hline
\end{tabular}

Note: Values are compared with significant level of 0.05, F V- First Visit, L V- Last Visit.

In this study, the significant mean difference is examined through the application of ' $t$ ' test. The computational methodology is discussed here:

\section{A good diet to control diabetes:}

The DASH or Dietary Approaches to Stop Hypertension is a lifelong approach to healthy eating designed to lower or prevent high blood pressure. It encourages dieters to avoid sodium consumption and eat foods high in nutrients such as calcium, potassium and magnesium.In addition to restricting sodium, the DASH diet is low in saturated fat and cholesterol. It includes lots of vegetables, fruits, low-fat dairy products and whole grains.

Hypothesis 5: There is no significant difference between change in calorie intake before and after treatment:

$$
\begin{aligned}
& T\left(X_{1}, X_{2}\right)=\frac{\bar{x}_{1}-\bar{x}_{2}}{\sqrt{\left(\frac{1}{n_{1}}+\frac{1}{n_{2}}\right)\left(\frac{\left(n_{1}-1\right) s_{1}^{2}+\left(n_{2}-1\right) s_{2}^{2}}{n_{1}+n_{2}-2}\right)}} \\
& =\frac{1259.35-1280.08}{\sqrt{\left(\frac{1}{376}+\frac{1}{376}\right)\left(\frac{(376-1)(359.24)^{2}+(376-1)(355.18)^{2}}{376+376-2}\right)}}
\end{aligned}
$$




$$
\approx-0.80 \quad \frac{-20.73}{\sqrt{679.983}}
$$

The result clearly demarks that there is no significant changes in the calorie intake before and after treatment.

\section{Hypothesis 6: There is no significant difference between change in Fibre content before and after treatment.}

$$
\begin{aligned}
& T\left(X_{1}, X_{2}\right)=\frac{\bar{x}_{1}-\bar{x}_{2}}{\sqrt{\left(\frac{1}{n_{1}}+\frac{1}{n_{2}}\right)\left(\frac{\left(n_{1}-1\right) s_{1}^{2}+\left(n_{2}-1\right) s_{2}^{2}}{n_{1}+n_{2}-2}\right)}} \\
& =\frac{4.75-15.43}{\sqrt{\left(\frac{1}{376}+\frac{1}{376}\right)\left(\frac{(376-1)(14.51)^{2}+(376-1)(13.23)^{2}}{376+376-2}\right)}} \\
& \approx-10.54
\end{aligned}
$$

This result shows that there is a significant change in Fibre content before and after treatment.

To conclude above the results, Abnormal glucose tolerance is present in more than $60 \%$ of adults older than 60 years of age as a result of a decrease in glucose tolerance as a result of decreased insulin sensitivity and impairment of pancreatic beta-cell function. The elderly diabetic population stands to benefit enormously from streamlining and optimizing diet planning in order to enhance longevity, minimize complications, and improve quality of life.

\section{CONCLUSION}

The Chi-Square test is conducted in order to identify statistical significance of demographic factors, family history and personal habits with respect to diabetes, particularly to explore the association across different age groups and diabetes prevalence. Table 2 shows the results considering a significant level of 0.05 . The result demonstrated a highly significant prevalence among age groups and prevalence of diabetes. This means that those with older age had higher likelihood to develop diabetes than those with younger age. It signifies that age is a significant influencing factor for diabetes. Further the test result also shows that diabetes is hereditary and caused by bad habits such as alcoholic and smoking, and, there is no association between exercise and diabetics before visiting to hospital.

\section{ACKNOWLEDGEMENTS}

We gratefully acknowledge the Dr. Mohan diabetes specialities centre database for providing the data for research and help.

\section{REFERENCES}

[1] Ward BW, Schiller JS and Goodman RA. Multiple chronic conditions among US adults: a 2012 update. Prev Chronic Dis.2014;11:E62.

[2] International Diabetes Federation. The diabetes atlas, 3rd ed., Brussels: International Diabetes Federation; 2006.

[3] International Diabetes Federation. The IDF diabetes atlas, 4th ed., Brussels: International Diabetes Federation; 2009.

[4] Michael W King, 1996-2017 the medical biochemistry page.org, LLC | info @ themedicalbiochemistrypage.org

[5] Neel JV. Diabetes mellitus: a "thirty" genotype rendered detrimental by "progress"? Am J Hum Genet 1962;14:353-62.

[6] Tuomilehto J, Lindstrom J, Eriksson JG, Valle TT, Hamalainen H and Ilanne - Parikka P. Prevention of type 2 diabetes mellitus by changes in lifestyle among subjects with impaired glucose tolerance. N Engl J Med 2001;344:1343-50. 
[7] Helmrich SP, Ragland DR, Leung RW and PaffenbargerJr RS. Physical activity and reduced occurrence of non-insulin dependent diabetes mellitus. N ENGL j Med 1991;325:147-53.

[8] Bassuk SS and Manson JE. Epidemiological evidence for the role of physical activity in reducing risk of type 2 diabetes and cardiovascular disease. J ApplPhysiol 2005;99:1193-204

[9] Hu FB, Manson JE, Stampfer MJ, Colditz G, Liu S and Solomon CG. Diet, lifestyle, and the risk of type 2 diabetes mellitus in women. N Engl J Med 2001;345:790-7

[10] Salmeron J, HU FB, Manson JE, Stampfer MJ, Colditz GA and Rimm EB. Dietary fat intake and risk of type 2 diabetes in women. Am J ClinNutur 2001;73:1019-26.

[11] Anderson JW, Randles KM, Kendall CWand Jenkins D J. Carbohydrate and fiber recommendations for individuals with diabetes: a quantitative assessment and meta-analysis of the evidence. J Am CollNutr 2004;23:5-17.

[12] Colditz GA, Willet WC, Stampfer MJ, Manson JE, Hennekens CH and Arky RA. Weight as a risk factor for clinical diabetes in women. Am J Epidemiol 1990;132:501-13.

[13] Wang Y, Rimm EB, Stampfer MJ, WILLETT WC and Hu FB. Comparison of abdominal adiposity and overall obesity in predicting risk of type 2 diabetes among men. Am J ClinNutr 2005;31:555-63.

[14] Koppes LL, Dekker JM, Hendriks HF, Bouter LM and Heine RJ. Moderate alcohol consumption lowers the risk of type 2 diabetes: a meta-analysis of prospective observational studies. Diabetes Care 2005;28:719-25.

[15] Carlsson S, Hammar N and Grill V. Alcohol consumption and type 2 diabetes: meta analysis of epidemiological studies indicates a U-shaped relationship. Diabetologia 2005;48:1051-4.

[16] Willi C, Bodenmann P, Ghali WA, Faris PD and Cornuz J. Active smoking and the risk of type 2 diabetes: a systematic review and meta analysis. JAMA 2007;298:2654-64.

[17] Gangwisch JE, Heymsfied SB, Boden-Albala B, Buijs RM, Kreier F, and Pickering TG. Sleep duration as a risk factor for diabetes incidence in a large US sample. Sleep 2007;30:1667-73.

[18] Chao CY, wujs, Yang YC, Shin CC, Wang RH and Lu FH. Sleep duration is a potential risk factor for newly diagnosed type 2 diabetes mellitus. MetabClinExp 2011;60:799-804.

[19] World Health Organization. 2008-2013 action plan for the global strategy for the prevention and control of non-communicable disease. Geneva: WHO;2008.

[20] Schulze MB, Heidemann C, Schienkiewitz A, Bergmann MM, Hoffmann K and Boeing H. Coparison of anthropometric characteristics in predicting the incidence of type 2 diabetes in the EPIC-Potsdam study. Diabetes Cars 2006;29:1921-3

[21] Nyamdorj R, Qiao Q, Soderberg S, Pitkaniemi JM, Zimmet PZ and Shaw JE. BMI compared with central obesity indicators as a predictor of diabetes incidence in Mauritius. Obesity 2009; 17:342-8.

[22] Jia z, Zhou Y, Liu X, Wang Y, Zhao X and Wang Y. Comparison of different anthropometric measures as predictors of diabetes incidence in a Chinese population. Diabetes Res ClinPract 2011;92:265-71.

[23] Lonn M, Mehlig, Bengtsson C and Lissner L. Adipocyte size predicts incidence of type 2 diabetes in women. Faseb J 2010;24:326-31. 


\section{AUTHORS' BIOGRAPHY}

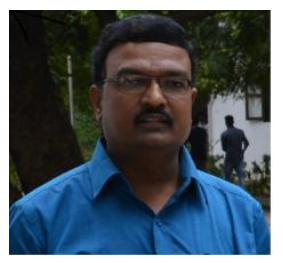

P. Sankar, Assistant Professor in Mathematics, Guru Nanak College, Chennai has an in depth knowledge in Mathematics and a well experienced teacher with 21 years of experience. His field of specialization is Analytic Number Theory.

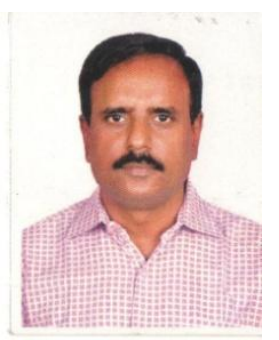

Dr. M.G. Ragunathan, Associate Professor in Zoology, Guru Nanak College, Chennai has a vast experience of 29 years in both teaching and Research. He has guided more than $25 \mathrm{Ph} . \mathrm{D}$., and guiding 9 students currently. He has a publication list of more than 120 papers in reputed refereed journals of high impact value. He is a council member in the Indian Science Congress Association.

Citation: P. Sankar et al., " Mathematical Predictions of Neuropathic Diabetes from Unit Level Data ", International Journal of Scientific and Innovative Mathematical Research, vol. 5, no. 5, p. 10, 2017., http://dx.doi.org/10.20431/2347-3142.0505004

Copyright: (C) 2017 Authors. This is an open-access article distributed under the terms of the Creative Commons Attribution License, which permits unrestricted use, distribution, and reproduction in any medium, provided the original author and source are credited. 